\title{
Solid Particle Erosion Behavior of Volcanic Ash/PVC Composites
}

\author{
O. ÇOBAN* \\ Kocaeli University, School of Civil Aviation, 41285 Izmit, Turkey
}

\begin{abstract}
In this study an attempt has been made to evaluate the solid particle erosion behavior of PVC based composites with various volcanic ash (VA) concentrations (5, 10, 15, 20 and 25 wt.\%). VA/PVC composites were prepared by using a twin screw micro-compounder and an injection molding machine. The erosion testing of VA/PVC composites was performed in accordance with the ASTM G76-95 standard at 6 different particle impingement angles $\left(15^{\circ}, 30^{\circ}, 45^{\circ}, 60^{\circ}, 75^{\circ}\right.$ and $\left.90^{\circ}\right)$ and under the pressure of 1.5 bar by using abrasive $\mathrm{Al}_{2} \mathrm{O}_{3}$ particles. The morphology of eroded surfaces was examined by using a scanning electron microscope (SEM), and possible wear mechanisms were discussed. Moreover, the surface roughness values of eroded VA/PVC composites were analyzed by using a non-contact laser optical profilometer. 3D surface topographies were also examined.
\end{abstract}

DOI: $10.12693 /$ APhysPolA.127.998

PACS: 81.05.Qk

\section{Introduction}

Solid particle erosion is a process of progressive removal of material from a target surface due to the repeated impact of solid particles of the soil elements, lifted by the wind $[1,2]$. Solid particle erosion generally leads to negative effects, such as wear of components, surface roughening and degradation, macroscopic scooping appearance, and reduction in the functional life of the structure $[2,3]$. Polyvinyl chloride (PVC) is known as very attractive and suitable polymer for building applications, such as window profiles, drain tubes, clading and siding, with its low cost and good performance [4-8]. A number of studies about PVC composites have been made by including various fillers to minimize damage of the polymer under outdoor conditions. However, the knowledge of filler effects on wear resistance of PVC is limited, and for the solid particle erosion behavior of PVC, the data is not available [9]. Volcanic ash (VA) is known as a mesoporous material, which usually has high specific surface area, significant porosity, and an appropriate pore structure, which enhances their ability to control the humidity in the environment [10]. Due to these properties, the use of VA as an alternative filler material in polymers can lead to both, a global cost reduction of final product, and a possibility for countries to use their natural VA resources. For these reasons, the effect of VA addition on solid particle erosion behavior of PVC was studied and reported.

\section{Materials and methods}

\subsection{Materials}

PVC (D100 TE) which used as the matrix resin for the micro-compounding and injection molding was provided

*e-mail: onur_coban@yahoo.com by Ankara Granül Co in Turkey. The D100 TE is of an unfilled grade for extrusion applications and has a density of $1.37 \mathrm{~g} / \mathrm{cm}^{3}$. VA samples were taken from Güneyda $\breve{g}$ tuff ring, which is located $13 \mathrm{~km}$ southwest of Nevşehir, Turkey. Nearly all vitric grains are angular and highly vesicular. Density and porosity parameters, determined by helium pycnometer and mercury porosimeter, are 1.8$2.4 \mathrm{~g} / \mathrm{cm}^{3}$ and $36-55 \%$, respectively.

\subsection{Sample preparation}

$\mathrm{VA} / \mathrm{PVC}$ composite materials were prepared by melt compounding and injection molding processes. DSM Xplore $15 \mathrm{ml}$ micro-compounder was used for melt compounding with a maximum processing temperature of $400{ }^{\circ} \mathrm{C}$ and a co-rotating twin screw speed of $250 \mathrm{rpm}$. DSM Xplore $12 \mathrm{ml}$ injection molding machine was used for injection molding of compounded melt. Maximum processing and mold temperatures are $400{ }^{\circ} \mathrm{C}$ and $200{ }^{\circ} \mathrm{C}$, respectively. The maximum pressure capacity of the machine is 16 bar. All the samples were compounded at $195{ }^{\circ} \mathrm{C}$ with $40 \mathrm{rpm}$ of screw speed and then injected in to the mold at $50{ }^{\circ} \mathrm{C}$ with an injection pressure of 10 bar.

\subsection{Solid particle erosion test}

Solid particle erosion tests were carried out according to ASTM G76-07. Figure 1a shows a schematic illustration of the erosion test rig used in this study. Sharpedge alumina $\left(\mathrm{Al}_{2} \mathrm{O}_{3}\right)$ particles with a size of 120 mesh $(\approx 125 \mu \mathrm{m})$ were driven by a static pressure of 1.5 bar during 10 seconds. Sharp-edge shape and approximate size $(125 \mu \mathrm{m})$ of alumina particles can be clearly seen in scanning electron microscope (SEM) photo shown in Fig. 1b. In this study, samples were eroded under six impingement angles of $15^{\circ}, 30^{\circ}, 45^{\circ}, 60^{\circ}, 75^{\circ}$ and $90^{\circ}$. Samples were cleaned by air blasting before and after erosion tests in order to remove sand and dust particles, and then were weighed in an electronic balance of an accuracy of $\pm 0.1 \mathrm{mg}$. 


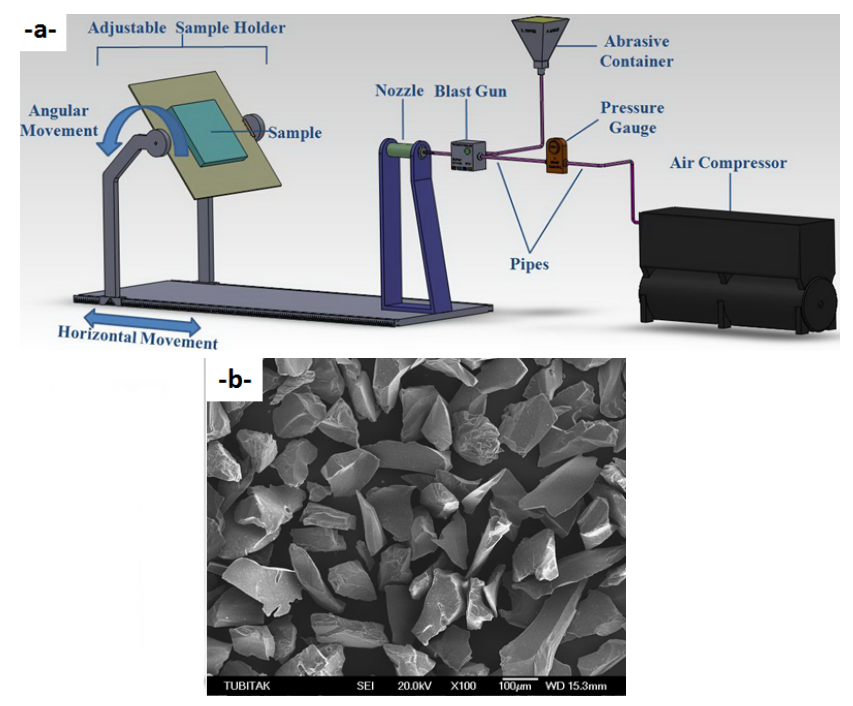

Fig. 1. (a) Erosion test rig, (b) Alumina $\left(\mathrm{Al}_{2} \mathrm{O}_{3}\right)$ erosion particle.

\subsection{Roughness measurement}

Surface roughness measurements of eroded samples were taken by using a Nanovea PS50 optical profilometer according to ISO 25178. Nanovea 3D software was used for surface roughness scanning process. Mountains $3 \mathrm{D}$ analysis software was used to visualize $3 \mathrm{D}$ roughness maps.

\subsection{Scanning electron microscopy (SEM)}

Investigation of solid particle erosion mechanisms of eroded surfaces was performed by using Tescan Vega 2 SEM device after gold coating by Edwards Sputter Coater S150B.

\section{Results and discussion}

Solid particle erosion results of PVC with the addition of VA are illustrated in Fig. 2. It is clear from Fig. 2a that pure PVC exhibited ductile erosion behavior, and that the maximum erosion rate was observed at the impingement angle of $30^{\circ}$. Additionally the minimum erosion rate of pure $\mathrm{PVC}$ was observed at the impingement angle of $90^{\circ}$. This typical ductile erosion behavior was also reported by various researchers [11-13]. It is seen from Fig. $2 \mathrm{~b}$ that the erosion rate increases almost linearly with the increase of VA content for all impingement angles. Hence, the addition of VA filler does not help in improving erosion resistance of $\mathrm{PVC}$, and the increase in VA content does not change the ductile erosion behavior of PVC. 3D roughness maps of PVC composites are shown in Fig. 3. Colour scale shows the variation of erosion depth for the erosion region.

At $30^{\circ}$ impingement angle, elliptic erosion regions were observed, which have almost equal area for pure and 25 wt.\% VA filled PVC. Additionally, according to colour change in erosion area, addition of 25 wt.\% of VA filler tended to result in a deeper erosion area, which is approximately $350 \mu \mathrm{m}$, compared to approximately $275 \mu \mathrm{m}$
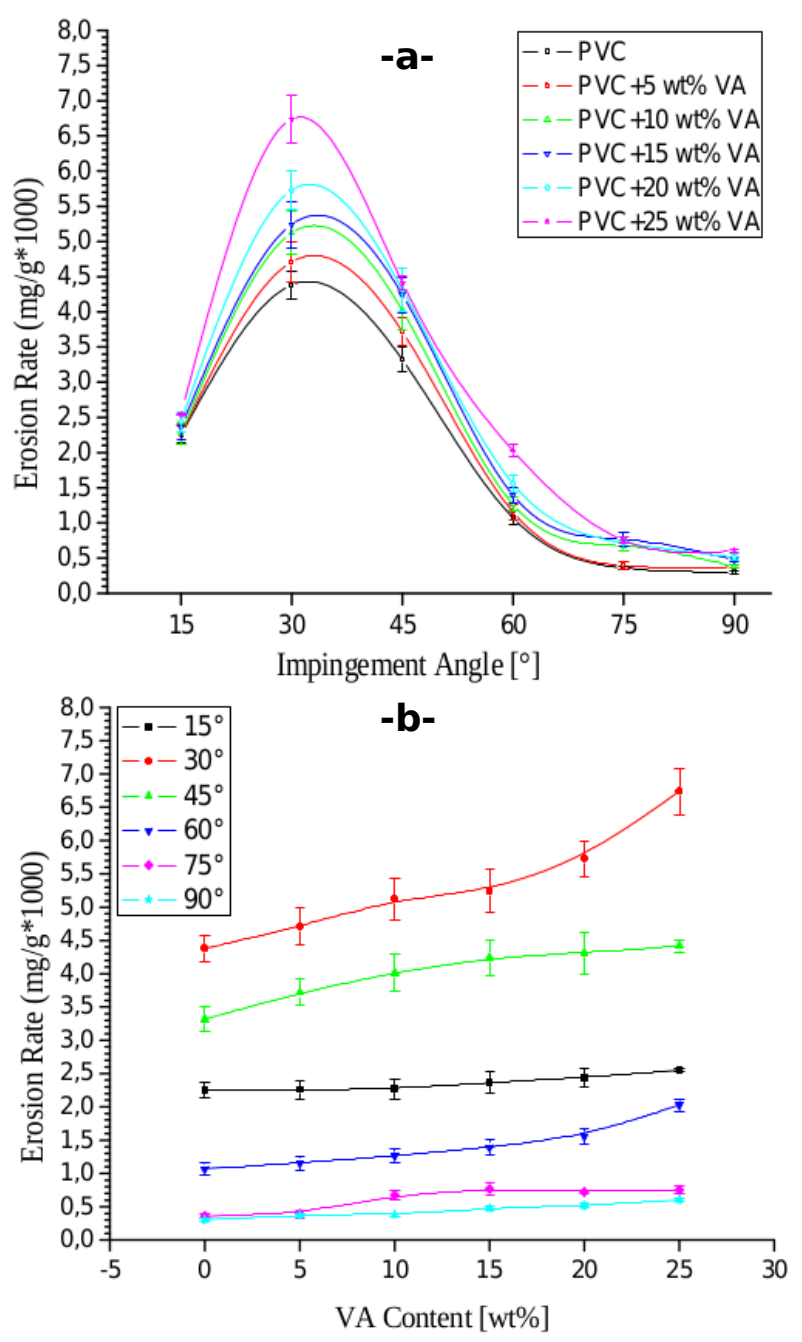

Fig. 2. Erosion rate variation of PVC/VA composites; a) as a function of impingement angle, b) as a function of VA content.

erosion area depth of pure PVC. Thus it can be said that deeper erosion areas obtained with the increase of VA content resulted in an increase of erosion rate of $\mathrm{PVC}$ at $30^{\circ}$ impingement angle. At the impingement angle of $90^{\circ}$, a circular erosion regions were observed, which have almost equal area for pure and $25 \mathrm{wt} . \% \mathrm{VA}$ filled PVC. However, a darker colour was seen in erosion area of pure PVC which could be attributed to embedding pits produced by impingement particles.

Surface morphology investigation of eroded surfaces was done to ascertain the wear mechanisms at $30^{\circ}$ and $90^{\circ}$ impingement angle. Surface morphologies indicate whether erosion has occurred by a ductile or brittle mechanism. In Fig. 4 surface photographs of pure and 25 wt.\% VA-filled PVC samples eroded at $30^{\circ}$ impingement angle show, that micro-cutting, micro-ploughing and material removal in the form of micro-chunks (white ellipses) have occurred during the erosion. It is clear that micro-chunks were seen to be more dominant with VA filler addition, because it is easy for matrix to break 
into small pieces and peel off from surface at the stable erosion stage in the presence of VA fillers.

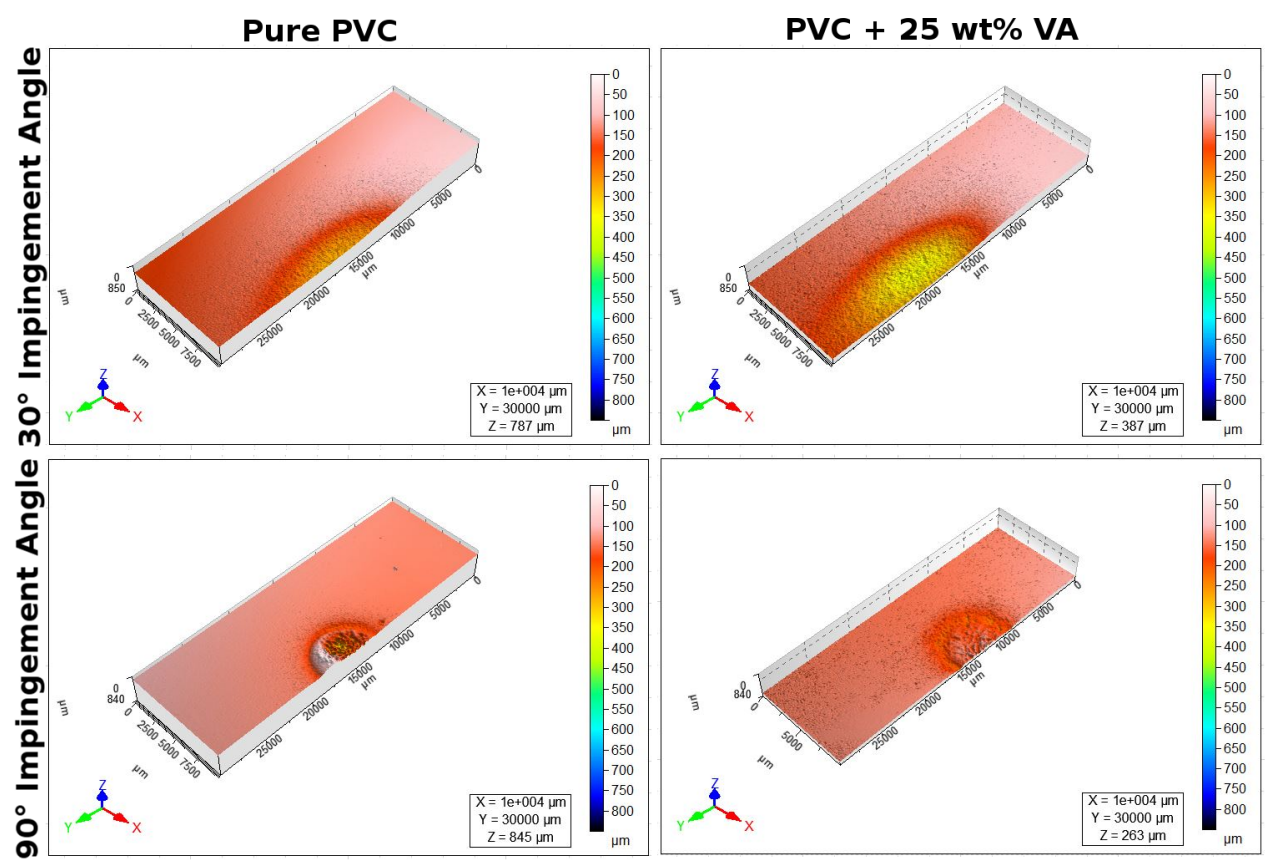

Fig. 3. Optical profilometer scans of pure and 25 wt.\% VA-filled PVC.
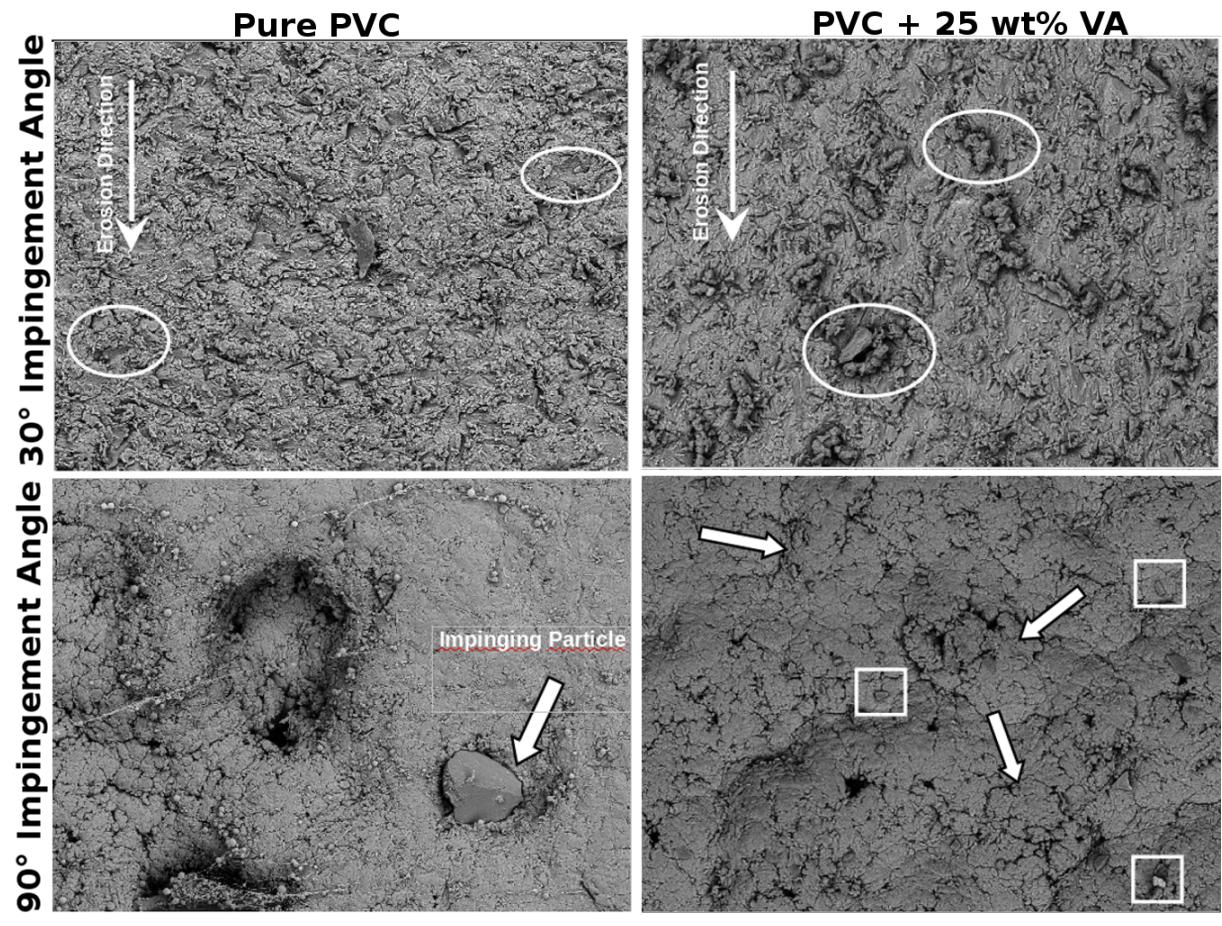

Fig. 4. SEM photographs $(250 \times)$ of pure and $25 \mathrm{wt} . \%$ VA-filled PVC, eroded at $30^{\circ}$ and $90^{\circ}$ impingement angles.

Erosion mechanisms of plastic deformation and microcracking (small white arrows) with fatigue failure were detected for impingement angle of $90^{\circ}$. Embedded impinging particles (big white arrow) were detected on pure
PVC surface during incubation period. At the end of incubation period, steady state erosion had started. At this stage the accelerated particles were impinging the embedded ones and the PVC matrix. This impact energy was 
absorbed by elastic deformation of PVC matrix, leading to availability of less amount of impact energy for plastic deformation, cracks initiation, local fracture and hence for the erosive wear [14]. During steady state erosion of VA-filled PVC composites, accelerated particles were impinging not only the PVC matrix but also the VA filler particles. VA particles were easily protruded under the erodent impingement action and the adhesion between VA particles and matrix was deteriorated. Finally VA particles were peeled off from the surface. That's why there is a small number of VA particles that can be seen (white squares) on the surface of VA-filled PVC sample. Impact energy was absorbed by less amount of elastic deformation, but with greater amount of plastic deformation and micro-cracking. These results indicate that 25 wt.\% VA-filled PVC composite is tougher than pure PVC [15]. However, it can be said that addition of VA filler did not change significantly the erosion behavior of $\mathrm{PVC}$ for impingement angle of $90^{\circ}$.

\section{Conclusions}

- Addition of VA filler did not change the ductile erosion behavior of PVC. Therefore maximum and minimum erosion rates were observed at $30^{\circ}$ and $90^{\circ}$ impingement angles, respectively.

- VA filler addition had a negative effect on erosion resistance of $\mathrm{PVC}$ at $30^{\circ}$ impingement angle. Because in the presence of VA particles, it is easy for matrix to break into small pieces and peel off from the surface.

- VA filler addition had no significant effect on erosion behavior of PVC at $90^{\circ}$ impingement angle.

- According to experimental results it can be said that VA particles should not be used as an alternative filler for PVC in solid particle erosion.

\section{References}

[1] B.K. Gandhi, S.V. Borse, Wear 257, 73 (2004).

[2] T. Sınmazçelik, N. Sarı, Polym. Compos. 31, 985 (2009).
[3] A.P. Harsha, A.A. Thakre, Wear 262, 807 (2007).

[4] C. Wang, H. Wang, J. Fu, G. Gu, Colloid. Surface. A 441, 544 (2014).

[5] W. Dierickx, Agr. Water Manage. 37, 109 (1998).

[6] L.E. Pimentel Real, A.M. Ferraria, A.M. Botelho do Rego, Polym. Test. 27, 743 (2008).

[7] L.E. Pimentel Real, A.M. Ferraria, A.M. Botelho do Rego, Polym. Test. 26, 77 (2007).

[8] I. Jakubowicz, Polym. Test. 20, 545 (2001).

[9] F. Yang, V. Hlavacek, Powder Technol. 103, 182 (1999).

[10] E. Avcu, O. Çoban, M.Ö. Bora, S. Fidan, T. Sinmazçelik, O. Ersoy, Polym. Compos. 35, 1826 (2014).

[11] J.J. Rajesh, J. Bijwe, U.S. Tewari, B. Venkataraman, Wear 249, 702 (2001).

[12] J. Bijwe, J. Indumathi, J.J. Rajesh, M. Fahim, Wear 249, 715 (2001).

[13] G.P. Tilly, W. Sage, Wear 16, 447 (1970).

[14] K. Friedrich, J. Mater. Sci. 21, 3317 (1986).

[15] Z. Huang, Z.Z. Li, X. Yuan, Wear 249, 1046 (2001). 